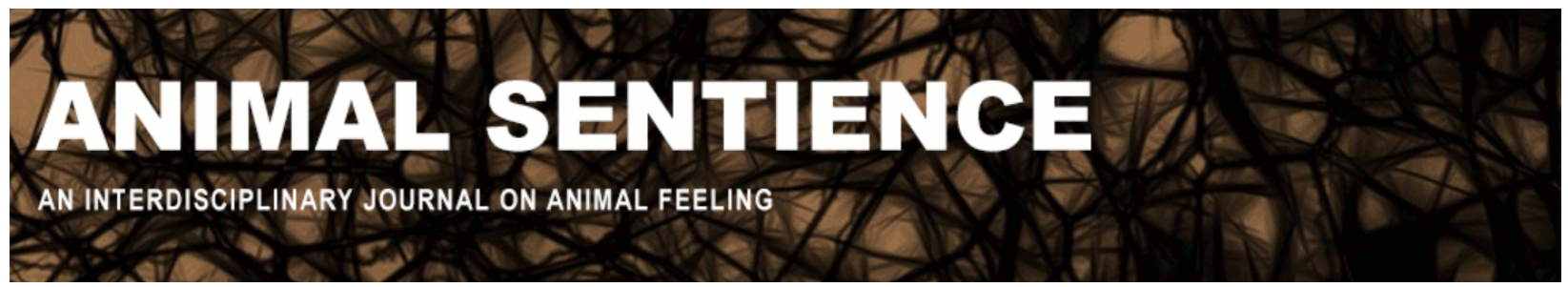

Lee, Phyllis C. (2019) Are octopuses special? Mind, sociality and life history. Animal Sentience 26(10)

DOI: $10.51291 / 2377-7478.1484$

Date of submission: 2019-06-10

Date of acceptance: 2019-06-12

(c)

This article has appeared in the journal Animal

Sentience, a peer-reviewed journal on animal

cognition and feeling. It has been made open access,

free for all, by WellBeing International and deposited

in the WBI Studies Repository. For more information,

please contact

wbisr-info@wellbeingintl.org.

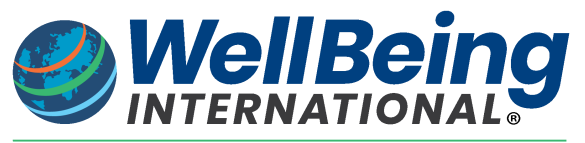

SOLUTIONS FOR PEOPLE, ANIMALS AND ENVIRONMENT 


\title{
Are octopuses special? Mind, sociality and life history
}

Commentary on Mather on Octopus Mind

\author{
Phyllis C. Lee \\ Psychology \\ University of Stirling, UK
}

\begin{abstract}
Understanding the Umwelt or being-ness of an octopus is a fascinating problem. Mather's review provides us with significant insights into the ways of living of non-humans that exploit a perceptual and physical world we can only guess at. Octopus "distributed minds" call into question our primate-based understandings of the importance of sociality and the pace of life in the evolution of complex perceptual and behavioural abilities.
\end{abstract}

Phyllis Lee has studied primates and elephants in the field for many years, with a particular focus on the life history of individuals from birth to death. Website

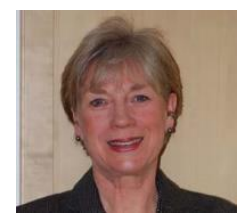

Mather's (2019) review of the behavioural capacities and cognitive abilities of octopuses is an effective response to Shettleworth's (1993) challenge regarding the anthropocentric programme in studies of comparative cognition. An octopus's "way of being," or Umwelt as described by Mather, appears to be that of physical and sensory coordination and organization, leading to a capacity for rapid learning, memory, and manipulation towards a desired or chosen outcome and rather exceptional spatial abilities. Such problem-solving abilities surely reflect some element of animal intelligence (or "higher-order reasoning processes"), as commonly defined.

At the same time and most interestingly, here is a group of species that clearly defies many of the "rules of life" operating in birds and most mammals. Most mammals trade the energetic requirements for reproduction against those for growth and maintenance, while octopods tradeoff between maintenance of the optic system and reproduction; the act of sexual reproduction results in death for males while some females survive just long enough for minimal parental care. Being an octopus thus means living a short and often solitary life in threedimensional space and many colours, but one that nonetheless requires considerable learning.

Do you need a mind, and specifically a social mind, to be smart (e.g., Humphrey, 1976)? Clearly, if an octopus, no. The construct of the social mind (large-brained animals, using specifically expanded brain regions to process social information; e.g., Dunbar \& Schultz, 2007) links the solving of ecological problems with explicitly social solutions. We see these patterns in species such as elephants, with the largest brains of any non-human terrestrial species and exceptionally complex, embedded social networks persisting across generations and for up to 1000 individuals. An elephant mind requires long-term (over 75 years) memory of place and individuals, threats and seasons along with inter-generational transfer of this knowledge. By contrast, an octopus needs to learn about its constantly dynamic, shifting, 3-dimensional 
environments rapidly, with survival benefits for a group of species with remarkably short lifespans of 5 months to a maximum of 5 years.

Despite their short, solitary lives, however, cephalopods can be classified into distinct temperament or personality types, which, when matched between partners, have been associated with more successful reproduction (Sinn et al., 2006). Some octopuses apparently do aggregate especially during mating, and some form size-based dominance hierarchies (Mather, 1985); so social assessments based on a kind of individual recognition may be possible (Tricarico et al., 2011). All of this is reviewed in detail in Mather (2019). But the general associations and linkages between sociality, longevity and complex learning observed in so many terrestrial mammals and birds appear to be disrupted for most octopods.

That octopods are adaptive "problem-solvers" seems not to bespeak imagination (e.g., Emory \& Clayton, 2004), but rather generalized activities directed towards a goal; and of course, they can learn. None of these leaning contexts, however, is that unusual even in short-lived taxa. Fruit flies learn about another individual's prior experiences from a visual cue (Mery et al., 2012), bumble bees can be trained to play football cooperatively (Loukola et al., 2017), and stick insects can play (Burghardt, 2005). None of these capacities implies that these species have selfawareness, imagination or even a generalized "mind," as the anthropocentric programme might suggest.

Does an understanding of the octopus Umwelt advance our perspectives on comparative cognition? It has long been known that terrestrial predators, requiring anticipatory actions against the movements and directions of their prey species, have larger brains than predicted for their body size alone (Eisenberg, 1981). Calculating an octopus Encephalisation Quotient, however, remains challenging. Gathering insights into the neural control of the octopus Umwelt gets to the heart of Chittka et al.'s (2012) proposition that comparative cognition studies require neurobiology - or, in the case of the octopus, an understanding of the embodied neural connections in a distributed brain (Mather \& Dickel, 2017). It challenges us to reexamine our very primate-centric concept of mind, memory and the consequences of sociality and a long, slow life history for intelligence (MacLean et al., 2012). So, while an octopus mind is nothing like a primate mind, nor indeed like a dog's, elephant's or bat's mind, it seems to this non-specialist to be just as interesting and important a mind as those we see among other terrestrial or airborne species. Restating the obvious, no non-primate's sensory abilities, perception, responses, memory or understanding of its world is similar to our own very primate perspective. Mather's detailed portrait of what it's like to be an octopus adds greatly to our appreciation of the diversity of cognitive abilities surrounding us, and should further shake us from our anthropocentric tree-top perspective.

\section{References}

Burghardt, G. M. (2005). The genesis of animal play: testing the limits. MIT Press.

Dunbar, R. I. M., \& Shultz, S. (2007). Evolution in the social brain. Science 317(5843): 1344-1347. Eisenberg, J. (1981). The mammalian radiations: an analysis of trends in evolution, adaptation, and behaviour. University of Chicago Press. 
Emery, N. J., \& Clayton, N. S. (2004). The mentality of crows: convergent evolution of intelligence in corvids and apes. Science 306(5703): 1903-1907.

Healy, S. D. (2012). Animal cognition: the trade-off to being smart. Current Biology 22(19): R840-R841.

Humphrey, N. K. (1976). The social function of intellect. In: Bateson, P.P.G. \& Hinde, R.A. (Eds.), Growing points in ethology: 303-318. Cambridge University Press.

Loukola, O. J., Perry, C. J., Coscos, L., \& Chittka, L. (2017). Bumblebees show cognitive flexibility by improving on an observed complex behavior. Science 355(6327): 833-836.

MacLean, E. L., Matthews, L. J., Hare, B. A., Nunn, C. L., Anderson, R. C., Aureli, F., ... \& Haun, D. B. (2012). How does cognition evolve? Phylogenetic comparative psychology. Animal Cognition 15(2): 223-238.

Mather, J. A. (1985). Behavioural interactions and activity of captive Eledone moschata: laboratory investigations of a 'social' octopus. Animal Behaviour 33(4): 1138-1144.

Mather, J. A. (2019). What is in an octopus's mind? Animal Sentience 26(1).

Mather, J. A., \& Dickel, L. (2017). Cephalopod complex cognition. Current Opinion in Behavioral Sciences 16: 131-137.

Mery, F., Varela, S. A., Danchin, É., Blanchet, S., Parejo, D., Coolen, I., \& Wagner, R. H. (2009). Public versus personal information for mate copying in an invertebrate. Current Biology 19(9): 730-734.

Shettleworth, S. J. (1993). Where is the comparison in comparative cognition? Alternative research programs. Psychological Science 4(3): 179-184.

Sinn, D. L., Apiolaza, L. A., \& Moltschaniwskyj, N. A. (2006). Heritability and fitness-related consequences of squid personality traits. Journal of Evolutionary Biology 19(5): 1437-1447.

Tricarico, E., Borrelli, L., Gherardi, F., \& Fiorito, G. (2011). I know my neighbour: individual recognition in Octopus vulgaris. PLOS ONE 6(4): e18710. 